\title{
Optimal common manufacturing cycle length for a multi-product inventory system with rework and an outside contractor
}

\author{
Singa Wang Chiu ${ }^{(1)}$, Hui-Cun Chen ${ }^{(2)}$, Hong-Dar Lin ${ }^{(2)}$ \\ (1) Department of Business Administration, Chaoyang University of Technology, Taichung 413, TAIWAN \\ (2) Department of Industrial Engineering and Management, Chaoyang University of Technology, Taichung 413, TAIWAN \\ e-mail: hdlin@cyut.edu.tw
}

\section{SUMMARY}

Facing global market's rigid competition, today's manufacturers need not only to satisfy the timely demands of multiproduct, but also to ensure quality of their goods. For the purpose of reducing fabrication cycle time so as to meet timely demands, outsourcing is always a helpful option in production planning. To address the aforementioned real issues, the present study derives the optimal common manufacturing cycle length for a multi-product inventory system, wherein a part of lot-size of each end product is supplied by an outside contractor, and in each cycle a rework process repairs random defects produced by the in-house process. The schedule of receipt time for outsourced items is practically assumed to be in the end of rework. A specific decision model is built to cautiously portray such a hybrid inventory problem. Through modeling, analysis, and derivation the expected annual system cost is obtained, and using optimization technique the optimal cycle length that minimizes system cost is gained. The proposed decision model not only can help find optimal solution to the problem, but also enables manufacturers to obtain diverse essential information, such as the critical outsourcing rate, individual manufacturing related cost for each end product, and influence or joint effects of variations in different system factor(s) on the problem. Without our in-depth exploration, the aforementioned information will still be unavailable to support managerial decision makings.

KEY WORDS: $\quad$ common manufacturing cycle length; multi-product inventory system; outsource; rework.

\section{INTRODUCTION}

The present research determines the optimal common manufacturing cycle length for a multiproduct inventory system with rework and an outside contractor. In real manufacturing processes, random defects are created due to diverse unpredictable causes. Sometimes, through rework process the defects can be repaired and become quality acceptable items. Yu 
S.W. Chiu, H-C Chen, H-D Lin: Optimal common manufacturing cycle length for a multi-product inventory system with rework and an outside contractor

and Bricker [1] used the Markov Chain techniques to analyze a multi-stage manufacturing problem. They provided informative application along with discusses. Besides, a mistake that existed in prior literatures for years was discovered and corrected. Grosfeld-Nir and Gerchak [2] studied multi-stage fabrication systems with the reworking capability of defective items in every stage. Uncertain defective rates are assumed in each stage and multiple runs may be required before obtaining sufficient finished items. At each stage, determination of small lots versus large lots becomes a major task in terms of cost savings. They indicated that if in the multi-stage system where only one set-up is required in one of the stages, the multi-stage system can then be simplified to a single-stage system. They proved that the best is if the required set-up exists in the first stage of the system. The recursive algorithms were presented to analyze and solve two- and three-stage systems where all stages require set-ups. Taleizadeh et al. [3] explored a multiproduct inventory system with the reworking of imperfect quality products. The objective of their study was to minimize the overall system cost under conditions of retaining the desired service level and limited budget. They showed that the objective function is convex, so the global optimality exists. Accordingly, they presented a solution procedure for the problem and used numerical illustrations along with sensitivity analyses to show applicability of their results and offered some important managerial insights of the problem. Extra studies [4-12] also addressed rework issues in diverse aspects of manufacturing systems.

With the aim of increasing utilization as well as satisfying customer's needs of diversified products, a multi-product manufacturing plan becomes manager's routine operating task. Rosenblatt and Finger [13] studied a single facility multi-product fabrication problem. Specifically, it was an electrochemical facility and its end products are different-size impact sockets for power wrenches. They proposed a specific grouping procedure for various end products and applied a revised version of an existing algorithm to ensure that the fabrication cycle lengths are the multiples of the shortest fabrication cycle time. van Eijs et al. [14] investigated multi-product inventory systems with combined replenishing expenses for constant deterministic demand. They proposed different heuristics to examine two separate strategies, namely the direct and indirect grouping strategies. Through simulation techniques, for each individual strategy and combined strategies, the performances were evaluated in terms of cost savings' percentages. The regression analysis was employed to summarize the input-output behavior from numerous simulation experiments they executed. Hennet [15] used the common cycle approach to examine a multi-stage fabrication planning problem. A cyclic economic lot-scheduling was constructed with the aim of solving such a problem in a job-shop environment. In each common cycle time, each job produces an end-item and its essential part in sufficient quantity so as to meet demands. The result indicated that the proposed cyclic economic lot-scheduling structure can be resolved in a decomposed way, and the solution can be put in use easily and also can be adjusted to deal with bounded stochastic demands. Additional papers [16-25] also studied different characteristics of multi-item manufacturing systems.

Moreover, in production planning, with the intention of shortening cycle length so as to meet timely demands, outsourcing is always a helpful option. Hong et al. [26] reviewed the usage of outside logistics services by Chinese producers including the present status and future views. They used the result of industry survey conducted in 2002. It revealed that there was significant difference between outside services' users and non-users, in particular in different characteristics of firm, such as type of industry, mode of fabrication, and size of account. With the purpose of cutting down risks connected with the transitional economy through transitory 
purchase from multiple vendors, mixed strategies were often used by many producers. They also found out that there was an increasing trend of outsourcing logistics' system design and information management. As to the dissatisfaction areas of outsourcing, they pointed outmainly those on on-time distribution performance, rate level, and service functions offerings. Paul and Yasar [27] studied the impacts of variations in subcontracting on productivity and input composition for Turkish textile and apparel production firms. For production firms that outsource inputs or outputs, they analyzed the differences in various indicators of performance, and disclosed that firms which contract out internationally perform better than those use domestic contractors. Their research also assessed labor productivity gaps and learnt that by initiating outsourcing many firms subsequently increase their productivity. They also evaluated the flexible fabrication function, and concluded that higher productivity from input subcontracting involves better skilled labor intensity, and the reverse is also true for output subcontracting. Pawar and Rogers [28] stated that uncertainty is a key factor that affects outsourcing decisions, and uncertainty is difficult to determine. They aimed at evaluating both the tangible and intangible costs of uncertainty in the outsourcing activities of manufacturing supply chains. In stage 1, they started with a survey through 107 questionnaires and 15 interviews from firms that implement subcontract of their fabrication, with the aim of understanding detailed relationships in subcontracting. The result revealed that most firms did not fully obtain their expected outsourcing benefits because of the uncertainty. In stage 2, five leading UK engineering companies were studied with the aim of understanding better and contextualizing the causes and consequences of tangible and intangible cost of uncertainty during subcontracting. As a result, a framework that contextualizes holistic costs of uncertainty was presented. Extra studies [29-33] also focused on different aspects of subcontracting/ outsourcing in manufacturing firms. This study determines the optimal common manufacturing cycle length for a multi-product inventory system with rework and an outside contractor. As little attention has been given to this particular area, we intend to fill the gap.

\section{ASSUMPTION AND DESCRIPTION OF THE PROBLEM}

This study derives the optimal common manufacturing cycle length for a multi-product inventory system with rework and an outside contractor. Consider demand $\lambda_{i}$ of $L$ end products (where $i$ equals to $1,2, \ldots, L$ ) in an inventory system must be satisfied by a batch manufacturing plan along with an outside contractor. Explicitly, with the aim of reducing common cycle length for each product $i$ in a cycle, a $\pi_{i}$ portion of lot size $Q_{i}$ is supplied by an outside contractor. While $\left(1-\pi_{i}\right) Q_{i}$ are manufactured in-house at a rate of $P_{1 i}$ items per year. It is assumed that a random defective rate $x_{i}$ is associated with product manufacturing process $i$, and the defective products are generated at rate of $d_{1 i}$ items per year (so, $d_{1 i}$ equals to $P_{1 i} x_{i}$ ). Furthermore, shortages are not permitted, consequently $\left(P_{1 i}-d_{1 i}-\lambda_{i}\right)$ greater than zero must hold. All defective items are assumed to be repairable, and for each product $i$, its rework process begins when uptime ends in the same cycle, at extra rework cost $C_{R i}$ per item. In the end of rework, the delivery of $\pi_{i} Q_{i}$ quantities brings inventory level to $H_{i}$ (see Figure 1 ). 
S.W. Chiu, H-C Chen, H-D Lin: Optimal common manufacturing cycle length for a multi-product inventory system with rework and an outside contractor

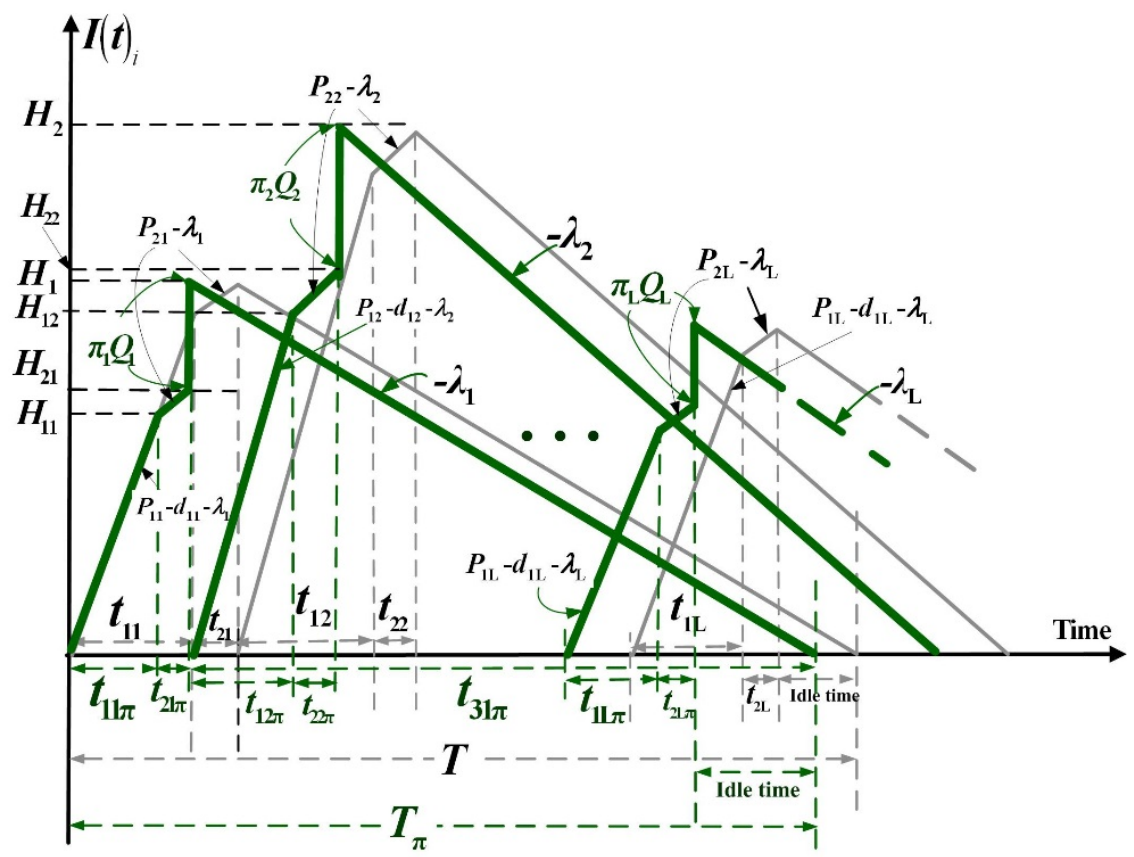

Fig. 1 On-hand level of finished end product $i$ in the proposed multi-product inventory system with rework and outside contractor

Additional notation employed in this study includes the following:

\begin{tabular}{|c|c|}
\hline$H_{1 i}$ & on-hand level of finished product $i$ when its uptime ends, \\
\hline$H_{2 i}$ & on-hand level of finished product $i$ when its rework time ends, \\
\hline$t_{1 i \pi}$ & manufacturing time for product $i$ \\
\hline$t_{2 i \pi}$ & rework time for product $i$ \\
\hline$t_{3 i \pi}$ & downtime for product $i$ \\
\hline$T_{\pi}$ & common manufacturing cycle length - decision variable, \\
\hline$E\left[x_{i}\right]$ & expected value of $x_{i}$ for product $i$ \\
\hline$C_{i}$ & unit manufacturing cost for product $i$ \\
\hline$C_{\pi i}$ & outside contractor's unit cost for product $i$ \\
\hline$\beta_{2 i}$ & the connecting factor between $C_{\pi i}$ and $C_{i,}$ \\
\hline$K_{i}$ & manufacturing setup cost for product $i$ \\
\hline$K_{\pi i}$ & outside contractor's setup cost of product $i$ \\
\hline$\beta_{1 i}$ & the connecting factor between $K_{\pi i}$ and $K_{i}$ \\
\hline$I(t)_{i}$ & on-hand level of finished end product i at time $t$, \\
\hline$h_{i}$ & unit holding cost of product $i$, \\
\hline$I_{D}(t)_{i}$ & on-hand level of defective product $i$ at time $t$, \\
\hline$h_{1 i}$ & unit holding cost per reworked product $i$ \\
\hline$T$ & $\begin{array}{l}\text { manufacturing cycle length in the proposed system without outside } \\
\text { contractor, }\end{array}$ \\
\hline$t_{1 i}$ & uptime for product $i$ in the proposed system without outside contractor, \\
\hline$t_{2 i}$ & $\begin{array}{l}\text { rework time for product } i \text { in the proposed system without outside } \\
\text { contractor, }\end{array}$ \\
\hline$t_{3 i}$ & downtime for product i in the proposed system without outside contractor, \\
\hline$T C\left(T_{\pi}\right)$ & overall cost in a replenishment cycle, \\
\hline$E\left[T C U\left(T_{\pi}\right)\right]$ & expected total cost per year, \\
\hline $\bar{x}$ & the average of $x_{i}$ \\
\hline $\bar{\pi}$ & the average of $\pi_{i}$ \\
\hline$\overline{C_{R}}$ & the average of $C_{R i}$ \\
\hline $\bar{C}$ & the average of $C_{i}$, \\
\hline$\overline{\beta_{1}}$ & the average of $\beta_{1 i}$ \\
\hline$\beta_{2}$ & the average of $\beta_{2 i}$. \\
\hline
\end{tabular}


Figure 2 exhibits on-hand level of defective product $i$ in the proposed multi-product inventory system with rework and outside contractor. It shows that the maximum level of defective product $i$ is $d_{1 i} t_{1 i \pi}$. During downtime $t_{3 i \pi}$ all finished inventories of product $i$ are depleted, then, the next manufacturing cycle initiates (Figure 1 ).

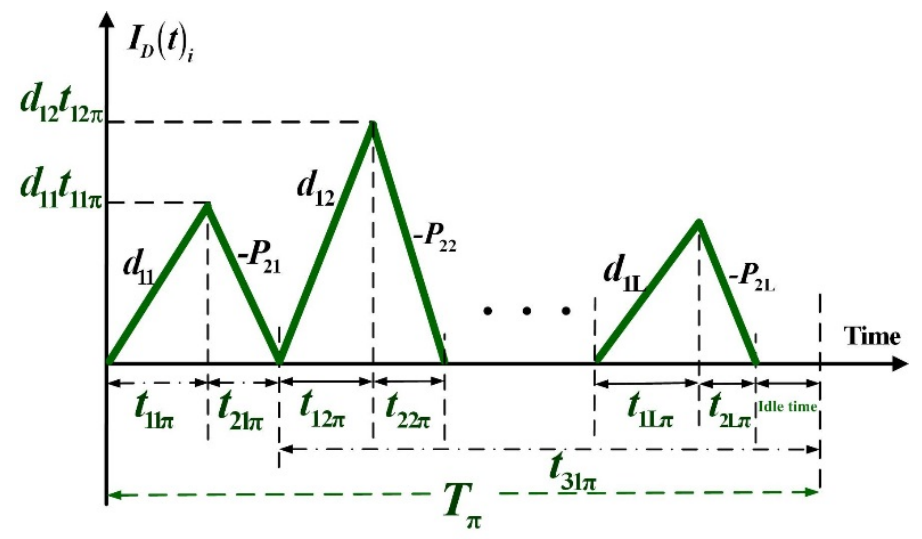

Fig. 2 On-hand level of defective product i in the proposed multi-product inventory system

\section{MATHEMATICAL MODELING, ANALYSIS AND OPTIMAL SOLUTION}

First of all, for a multi-product inventory system with rework and an outside contractor, the summation of manufacturing uptimes and rework times of all $L$ products must meet the following requirement:

$$
\sum_{i=1}^{L}\left[\left(\frac{\left(1-\pi_{i}\right) \lambda_{i}}{P_{1 i}}\right)+\left(\frac{\left(1-\pi_{i}\right) \lambda_{i} E\left[x_{i}\right]}{P_{2 i}}\right)\right]<1
$$

That is, a single machine has sufficient capacity to perform the fabrication and rework processes. Then, the following system equations can be simply observed from the proposed model, especially from Figures 1 and 2:

$$
\begin{gathered}
T_{\pi}=t_{1 i \pi}+t_{2 i \pi}+t_{3 i \pi} \\
H_{1 i}=\left(P_{1 i}-\lambda_{i}-d_{1 i}\right) t_{1 i \pi} \\
t_{1 i \pi}=\frac{H_{1 i}}{P_{1 i}-\lambda_{i}-d_{1 i}}=\frac{\left(1-\pi_{i}\right) Q_{i}}{P_{1 i}} \\
Q_{i}=\lambda_{i} T_{\pi} \\
H_{2 i}=H_{1 i}+\left(P_{2 i}-\lambda_{i}\right) t_{2 i \pi} \\
t_{2 i \pi}=\frac{x_{i}\left[\left(1-\pi_{i}\right) Q_{i}\right]}{P_{2 i}} \\
d_{1 i} t_{1 i \pi}=x_{i} P_{1 i} t_{1 i \pi}=x_{i}\left[\left(1-\pi_{i}\right) Q_{i}\right] \\
H_{i}=H_{2 i}+\pi_{i} Q_{i}=\lambda_{i} t_{3 i \pi} \\
t_{3 i \pi}=\frac{H_{i}}{\lambda_{i}}
\end{gathered}
$$


Moreover, the relationships between costs from outside contractor and costs of manufacturing in-house are assumed as follows:

$$
\begin{gathered}
K_{\pi i}=\left(1+\beta_{1 i}\right) K_{i} \\
C_{\pi i}=\left(1+\beta_{2 i}\right) C_{i}
\end{gathered}
$$

where $-1<\beta_{1 i}<0$ and $\beta_{2 i}>0$ are reasonably assumed.

The overall cost in a replenishment cycle contains the sum of (i) manufacturing setup and variable costs, (ii) outside contractor's fixed and variable costs, (iii) cost for rework, and (iv) overall holding costs for perfect and defective (including reworked items) in the cycle as follows:

$$
T C\left(T_{\pi}\right)=\sum_{i=1}^{L}\left\{\begin{array}{l}
K_{i}+C_{i}\left(1-\pi_{i}\right) Q_{i}+K_{\pi i}+C_{\pi i}\left(\pi_{i} Q_{i}\right)+C_{R i} x_{i}\left[\left(1-\pi_{i}\right) Q_{i}\right] \\
+h_{i}\left[\frac{H_{1 i}+d_{1 i} t_{1 i \pi}}{2}\left(t_{1 i \pi}\right)+\frac{H_{1 i}+H_{2 i}}{2}\left(t_{2 i \pi}\right)+\frac{H_{i}}{2}\left(t_{3 i \pi}\right)\right]+h_{1 i} \frac{P_{2 i} t_{2 i \pi}}{2}\left(t_{2 i \pi}\right)
\end{array}\right\}
$$

Then, we apply the expected value $E\left[x_{i}\right]$ to Eq. (13) for dealing with randomness of $x_{i}$, and replace Eqs. (2) to (12) in Eq. (13), the following $E\left[T C U\left(T_{\pi}\right)\right]$ can be derived after extra efforts in derivations:

$$
\left.\begin{array}{l}
E\left[\operatorname{TCU}\left(T_{\pi}\right)\right]=\frac{E\left[T C\left(T_{\pi}\right)\right]}{E\left[T_{\pi}\right]}= \\
=\sum_{i=1}^{L} \frac{K_{i}\left(2+\beta_{1 i}\right)}{T_{\pi}}+\frac{h_{i} \lambda_{i} T_{\pi}}{2}+\lambda_{i}\left\{\begin{array}{l}
C_{i}\left(1-\pi_{i}\right)+C_{R i} E\left[x_{i}\right]\left(1-\pi_{i}\right)+\left(1+\beta_{2 i}\right) C_{i} \pi_{i} \\
+\frac{\lambda_{i} T_{\pi} E\left[x_{i}\right]^{2}\left(1-\pi_{i}\right)^{2}\left(h_{1 i}-h_{i}\right)}{2 P_{2 i}} \\
-\frac{h_{i} \lambda_{i} T_{\pi}\left(1-\pi_{i}\right)}{2}\left[\frac{\left(1+\pi_{i}\right)}{P_{1 i}}+\frac{2 E\left[x_{i}\right]\left(\pi_{i}\right)}{P_{2 i}}\right.
\end{array}\right]
\end{array}\right\}
$$

Apply first- and second-derivative of $E\left[T C U\left(T_{\pi}\right)\right]$, we have Eqs. (15) and (16) as follows:

$$
\begin{gathered}
\frac{d E\left[T C U\left(T_{\pi}\right)\right]}{d T_{\pi}}=\sum_{i=1}^{L} \frac{-K_{i}\left(2+\beta_{1 i}\right)}{T_{\pi}^{2}}+\frac{h_{i} \lambda_{i}}{2}+\lambda_{i}\left\{\begin{array}{l}
\frac{\lambda_{i} E\left[x_{i}\right]^{2}\left(1-\pi_{i}\right)^{2}\left(h_{1 i}-h_{i}\right)}{2 P_{2 i}} \\
-\frac{h_{i} \lambda_{i}\left(1-\pi_{i}\right)}{2}\left[\frac{\left(1+\pi_{i}\right)}{P_{1 i}}+\frac{2 E\left[x_{i}\right]\left(\pi_{i}\right)}{P_{2 i}}\right]
\end{array}\right\} \\
\frac{d^{2} E\left[T C U\left(T_{\pi}\right)\right]}{d T_{\pi}^{2}}=\sum_{i=1}^{L} 2\left[\frac{K_{i}\left(2+\beta_{1 i}\right)}{T_{\pi}^{3}}\right]
\end{gathered}
$$

Since $K_{i}, T_{\pi}$, and $\left(2+\beta_{1 i}\right)$ are all positive, Eq. (16) is also positive. That is, $E\left[T C U\left(T_{\pi}\right)\right]$ is convex for all $T_{\pi}$ values excluding zero. Finally, by setting the first-derivative of $E\left[T C U\left(T_{\pi}\right)\right]$ (Eq. (15)) equals zero, we solve and find $T_{\pi}{ }^{*}$ that minimizes expected total cost per year as follows:

$$
T_{\pi}^{*}=\sqrt{\frac{2 \sum_{i=1}^{L} K_{i}\left(2+\beta_{1 i}\right)}{\lambda_{i}\left[h_{i}+\frac{\lambda_{i} E\left[x_{i}\right]^{2}\left(1-\pi_{i}\right)^{2}\left(h_{1 i}-h_{i}\right)}{P_{2 i}}-h_{i} \lambda_{i}\left(1-\pi_{i}\right)\left[\frac{\left(1+\pi_{i}\right)}{P_{1 i}}+\frac{2 E\left[x_{i}\right]\left(\pi_{i}\right)}{P_{2 i}}\right]\right]}}
$$

Furthermore, if the summation of setup times $S_{i}$ is greater than the system's idle time, then cycle length must be larger than $T_{\min }$ (see Appendix A for detailed computations of $T_{\min }$ ). In 
summary, one should choose $\max \left(T_{\pi}^{*}, T_{\min }\right)[34]$ as the optimal cycle length for the proposed system whether the summation of $S_{i}$ is negligible or not.

\section{EXAMPLE}

Five distinct products are considered in the following example to explain applicability of the proposed multi-product inventory system with rework and an outside contractor. Table 1 exhibits the assumption of system variables in this example.

Table 1 Assumption of system variables in the example

\begin{tabular}{ccccccccccccccc}
\hline $\begin{array}{c}\text { Product } \\
\text { number }\end{array}$ & $\lambda_{i}$ & $C_{i}$ & $C_{R i}$ & $K_{i}$ & $P_{1 i}$ & $x_{i}$ & $h_{i}$ & $h_{1 i}$ & $\pi_{i}$ & $\beta_{1 i}$ & $\beta_{2 i}$ & $C_{\pi i}$ & $K_{\pi i}$ & $P_{2 i}$ \\
\hline 1 & 3000 & 80 & 50 & 10000 & 58000 & $5 \%$ & 10 & 30 & 0.4 & -0.60 & 0.40 & 112.0 & 4000 & 2900 \\
2 & 3200 & 90 & 55 & 11000 & 59000 & $10 \%$ & 15 & 35 & 0.4 & -0.65 & 0.35 & 121.5 & 3850 & 2950 \\
3 & 3400 & 100 & 60 & 12000 & 60000 & $15 \%$ & 20 & 40 & 0.4 & -0.70 & 0.30 & 130.0 & 3600 & 3000 \\
4 & 3600 & 110 & 65 & 13000 & 61000 & $20 \%$ & 25 & 45 & 0.4 & -0.75 & 0.25 & 137.5 & 3250 & 3050 \\
5 & 3800 & 120 & 70 & 14000 & 62000 & $25 \%$ & 30 & 50 & 0.4 & -0.80 & 0.20 & 144.0 & 2800 & 3100 \\
\hline
\end{tabular}

First of all, we calculate Eqs. (17) and (14) using variables' values assumed in Table 1, and obtain the optimal common manufacturing cycle length $T_{\pi}{ }^{*}=0.7002$ (in a year) and the optimal expected total cost per year $E\left[T C U\left(T_{\pi}^{*}\right)\right]=\$ 2,187,658$ (see Table B-1 in Appendix B). Also, from Table B-1 we found that product reworking cost in the proposed system is $\$ 51,555$ (or $2.36 \%$ of $E\left[T C U\left(T_{\pi}^{*}\right)\right]$ ).

Figure 3 shows the outcome of an investigation on the effect of changes in average outsourcing percentage $\bar{\pi}$ on $E\left[T C U\left(T_{\pi}^{*}\right)\right]$. It can be seen that the optimal system cost per year $E\left[T C U\left(T_{\pi}^{*}\right)\right]$ rises significantly, as $\bar{\pi}$ increases. A so-called critical ratio of $\bar{\pi}(=0.792)$ is uncovered, meaning once $\bar{\pi}>0.792$, the management should choose the more economic 'buy' decision (i.e., a $100 \%$ outsourcing policy; details please also refer to Table B-1).

In contrast, Figure 4 depicts exploratory result on impact of variations in average outsourcing rate $\bar{\pi}$ on entire utilization for the proposed multi-product system with rework and outside contractor. From Figure 4 , it is noted that entire utilization falls extensively, as $\bar{\pi}$ increases; and at $\bar{\pi}=0.4$ (as in our example) utilization falls to $43.16 \%$ from $71.93 \%$ (at $\bar{\pi}$ $=0$ ); yet, this fall in utilization is at the expense of $9.06 \%$ increase in $E\left[\operatorname{TCU}\left(T_{\pi}^{*}\right)\right]$ (refer to Table B-1).

The effect of differences in average outsourcing setup cost connecting factor $\overline{\beta_{1}}$ on total cost for each end product are studied and the outcome is illustrated in Figure 5. It points out that total cost for each product declines, as $\overline{\beta_{1}}$ decreases. For we assume negative values of $\overline{\beta_{1}}$ to portray the fact that in-house manufacturing setup cost is more costly than that of outsourcing plan. 
S.W. Chiu, H-C Chen, H-D Lin: Optimal common manufacturing cycle length for a multi-product inventory system with rework and an outside contractor

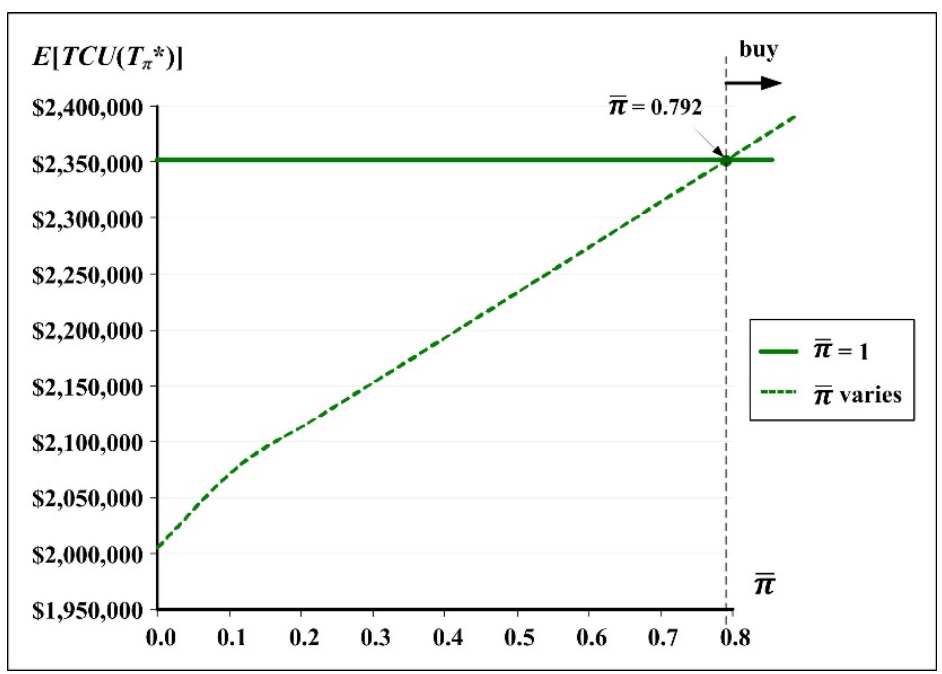

Fig. 3 Effect of changes in average outsourcing percentage on $E\left[T C U\left(T_{\pi}^{*}\right)\right]$

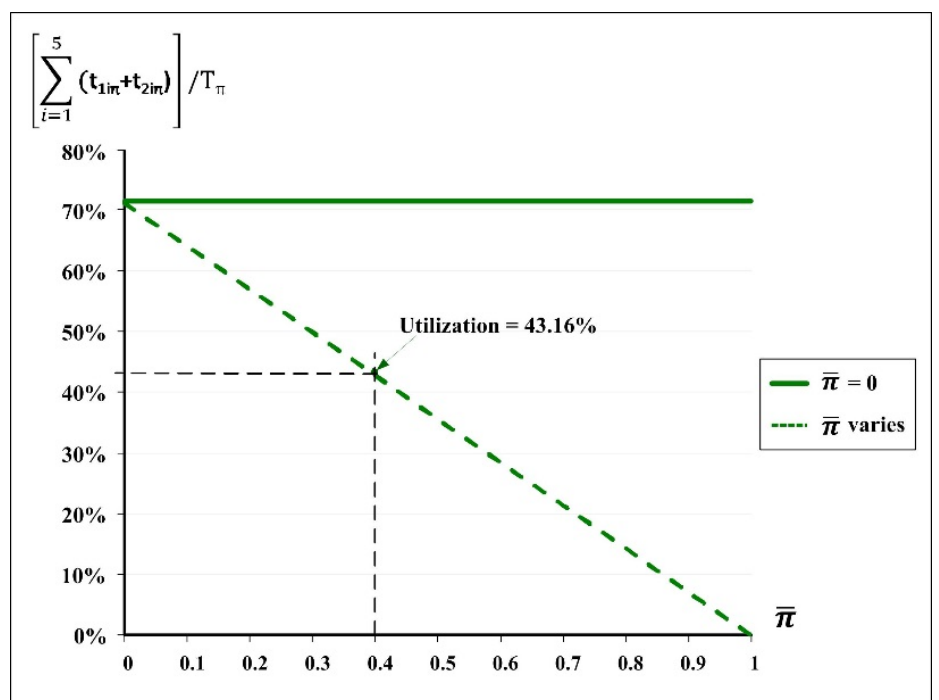

Fig. 4 Impact of variations in average outsourcing percentage on total utilization of the proposed system

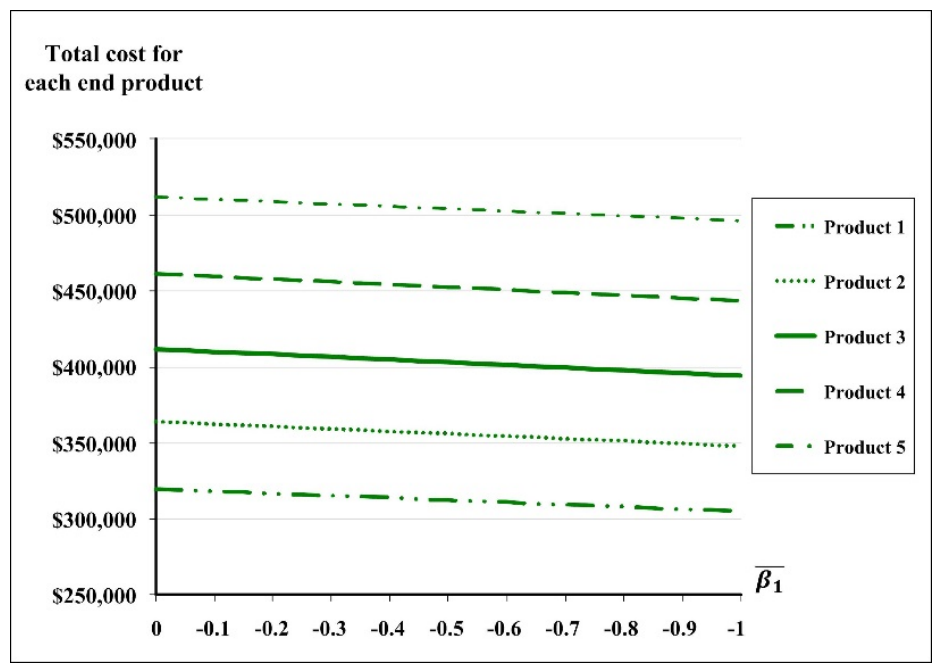

Fig. 5 Effect of differences in average $\beta_{1}$ on total cost for each end product 
Conversely, Figure 6 exhibits the impact of changes in average outsourcing unit cost connecting factor $\overline{\beta_{2}}$ on total cost for each end product. It indicates that as $\overline{\beta_{2}}$ increases, total cost for each product raises considerably. This reflects a real-life situation, i.e., unit cost for outsourced item is more expensive than that made by in-house process.

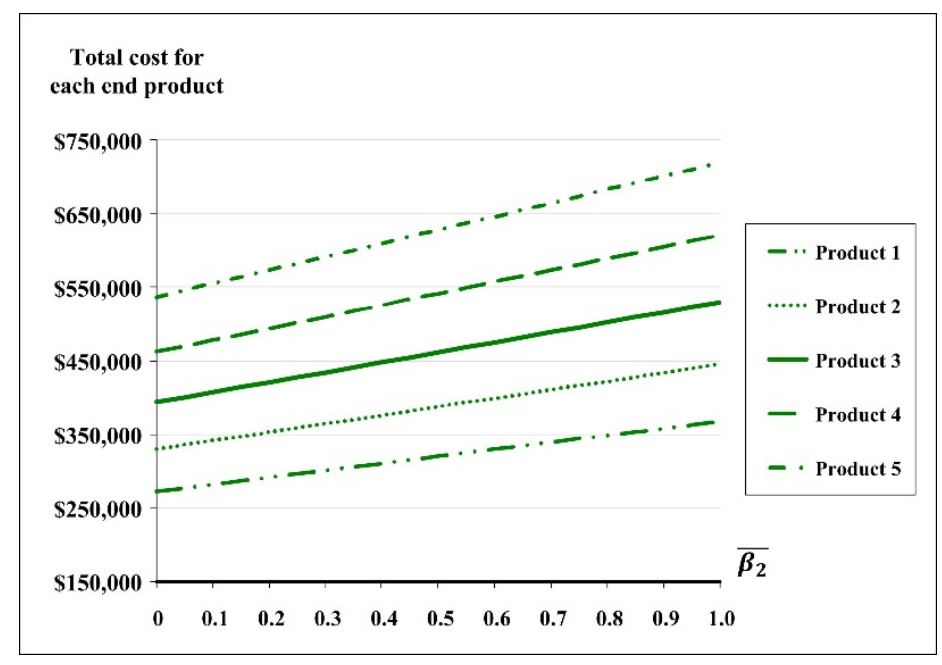

Fig. 6 The impact of changes in average $\beta_{2}$ on total cost for each end product

The result of further investigation on influence of variations in ratio of average unit rework cost over average unit manufacturing cost $\left(\overline{C_{R}} / \bar{C}\right)$ on $E\left[T C U\left(T_{\pi}^{*}\right)\right]$ is presented in Figure 7. It shows that as the $\overline{C_{R}} / \bar{C}$ ratio goes up, $E\left[\operatorname{TCU}\left(T_{\pi}^{*}\right)\right]$ increases accordingly; and $E\left[\operatorname{TCU}\left(T_{\pi}{ }^{*}\right)\right]=$ $\$ 2,187,658$, as we assume $\overline{C_{R}} / \bar{C}=0.6$ in our example.

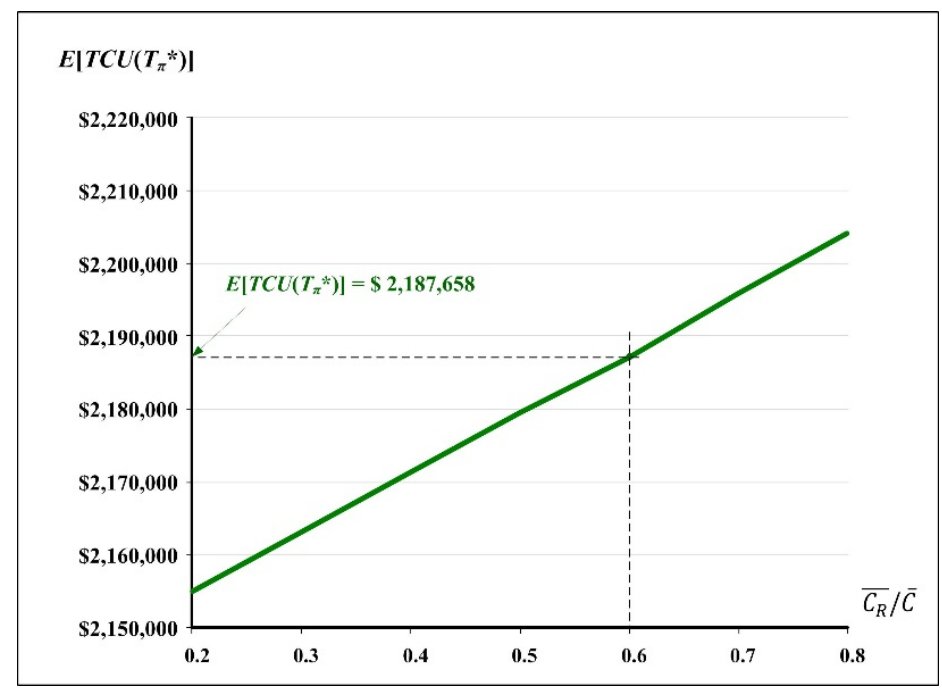

Fig. 7 Influence of variations in rework cost ratio on $\left.\operatorname{E[CU}\left(T_{\pi}^{*}\right)\right]$

Figure 8 displays the analytical outcome on the effect of changes in common manufacturing cycle length $T_{\pi}$ on distinct cost factors in the proposed system. It can be seen that as $T_{\pi}$ increases, inventory holding cost notably raises and rework cost goes up accordingly; but on the contrary, both in-house and outsourcing setup costs drops considerably. It is also noted 
S.W. Chiu, H-C Chen, H-D Lin: Optimal common manufacturing cycle length for a multi-product inventory system with rework and an outside contractor

that as $T_{\pi}$ deviates from its optimal point (i.e., 0.7002 (a year)), $E\left[\operatorname{TCU}\left(T_{\pi}\right)\right]$ increases drastically.

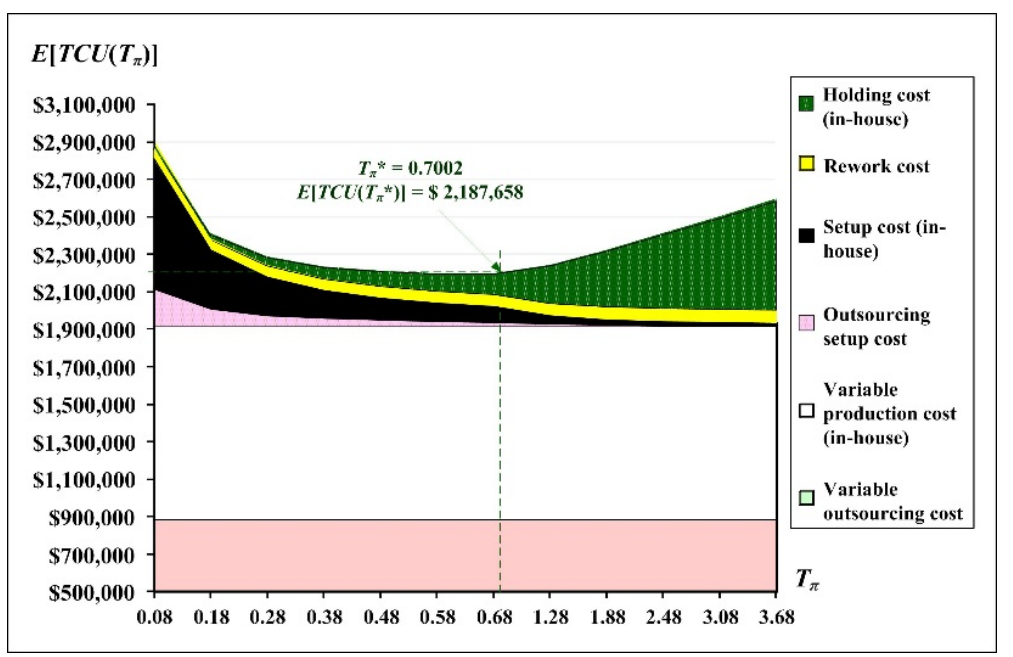

Fig. 8 Effect of changes in cycle length $T_{\pi}$ on distinct cost factors in the proposed system

Joint impacts of differences in rework cost (using $\overline{C_{R}} / \bar{C}$ ratio) and average outsourcing rate $\bar{\pi}$ on $E\left[\operatorname{TCU}\left(T_{\pi}^{*}\right)\right]$ are explored and the outcomes are illustrated in Figure 9. It is noted that $E\left[T C U\left(T_{\pi}^{*}\right)\right]$ increases considerably, as both $\overline{C_{R}} / \bar{C}$ and $\bar{\pi}$ raises. However, when $\bar{\pi}$ goes up to and beyond 0.8 , the effect of changes in $\overline{C_{R}} / \bar{C}$ on $E\left[\operatorname{TCU}\left(T_{\pi}^{*}\right)\right]$ becomes insignificant, due to that the amount of in-house manufacturing items is greatly reduced.

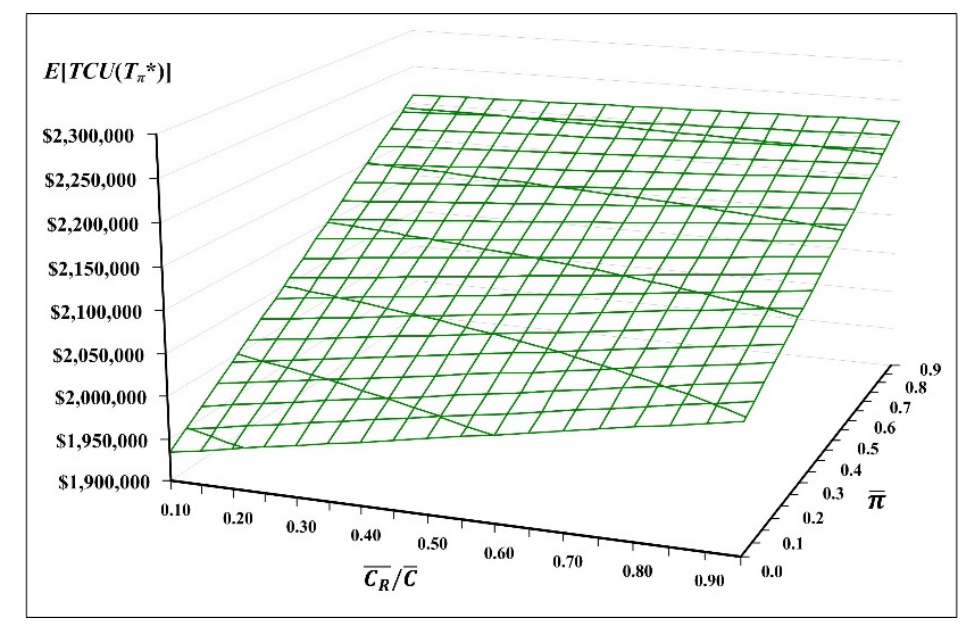

Fig. 9 Joint impacts of differences in rework cost ratio and average $\pi$ on $E\left[T C U\left(T_{\pi}^{*}\right)\right]$

Figure 10 depicts combined influences of variations in $\bar{\pi}$ and average defective rate $\bar{x}$ on total variable rework cost. It indicates that total variable rework cost increases dramatically, as $\bar{x}$ goes up and when $\bar{\pi}$ is smaller than 0.5; conversely, total variable rework cost declines severely, as $\bar{\pi}$ raises and when $\bar{x}$ is greater than 0.5 . The reason for the former is the large amount of in-house made items affected by $\bar{x}$; conversely, for the latter, the effect of $\bar{x}$ on total rework cost becomes insignificant, when there are outsized outsourcing items and not the inhouse made items. 
Moreover, extra investigative outcomes on the joint effects of changes in average outsourcing percentage $\bar{\pi}$ and average outsourcing unit cost connecting factor $\overline{\beta_{2}}$ on optimal manufacturing cycle length $T_{\pi}{ }^{*}$ are exhibited in Figure 11. It shows that $T_{\pi}{ }^{*}$ decreases a little, as $\overline{\beta_{2}}$ rises; however, $T_{\pi}^{*}$ declines significantly, as $\bar{\pi}$ increases.

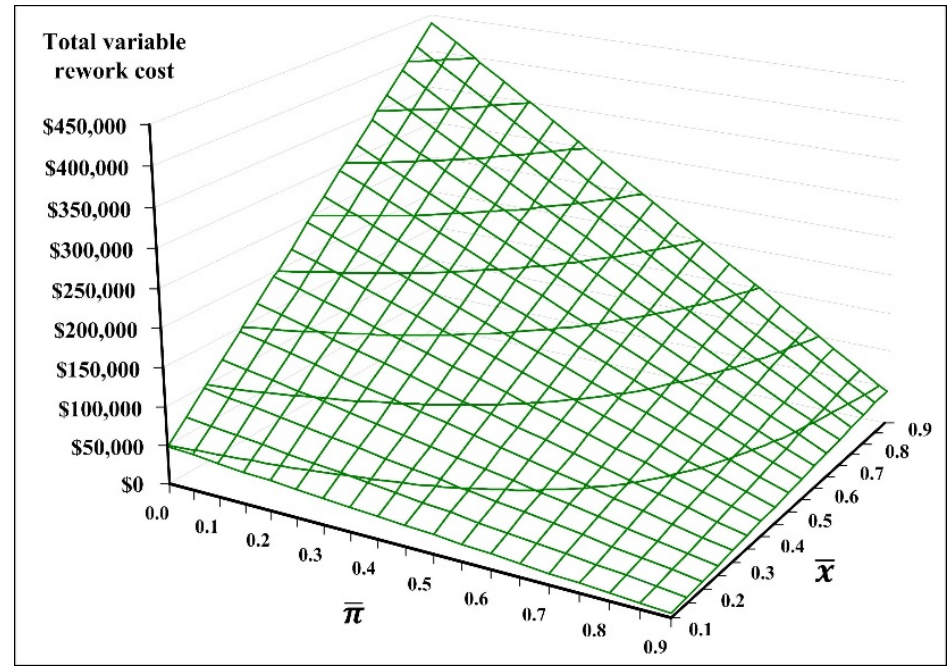

Fig. 10 Combined influences of variations in average $\pi$ and average $x$ on total variable rework cost

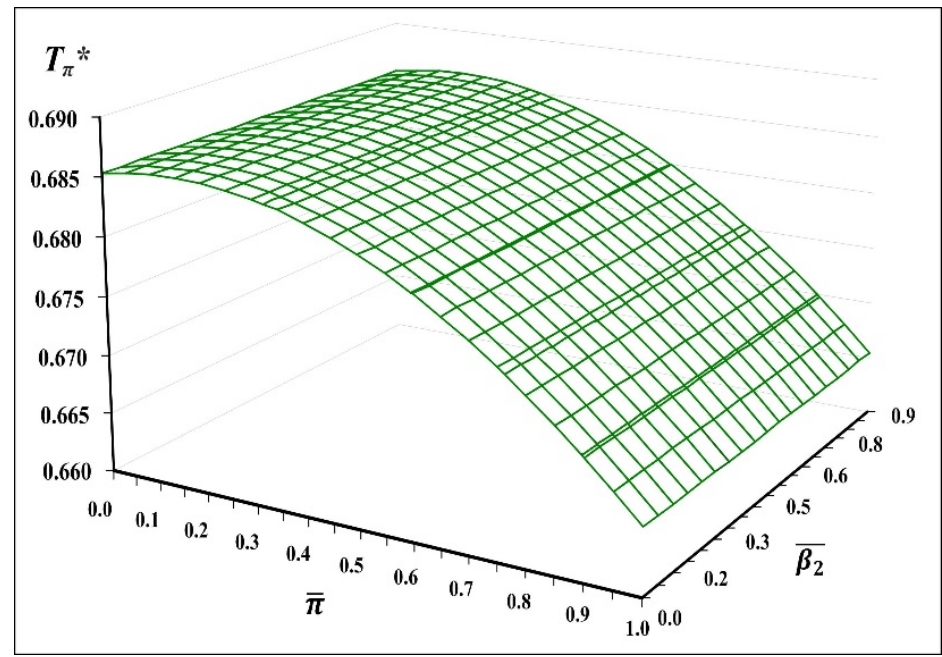

Fig. 11 Joint effects of changes in average $\pi$ and average $\beta_{2}$ on the optimal cycle length $T_{\pi}^{*}$

\section{CONCLUSIONS}

A multiproduct common manufacturing cycle length problem with rework and an outside contractor is explored. A specific decision model is built to cautiously portray this hybrid inventory refilling problem. Through modeling, analysis, and derivation the expected annual system cost is obtained, and using optimization technique the optimal cycle length that minimizes system cost is gained. Upon accomplishing this decision model, we are able to find now not only the optimal solution (see Figure 8), but also to expose various essential information of the problem that can support managerial decision makings. Such information 
includes critical outsourcing rate average $\pi$ (Figure 3), specific machine utilization (Figure 4), impact of changes in certain variables on individual cost of each end product (Figures 5-6); and influence or joint effects of variations in different system factor(s) on a particular cost, on $E\left[T C U\left(T_{\pi}^{*}\right)\right]$, and on $T_{\pi}^{*}$ (see Figure 7 and Figures 9-11)). For future study, an interesting research direction could be to explore the impact of random demand rates on the problem.

\section{APPENDIX}

\subsection{APPENDIX - A}

Detailed computations of $T_{\min }$ are provided as follows:

When (summation of setup times $S_{i}$ ) > (system's idle time), then $T_{\pi}{ }^{*}$ is no longer valid. One should make sure the following new cycle length $T_{\pi}$ hold, in order to guarantee that cycle time is adequately large to contain summation of setup, fabrication, and rework times for $L$ products:

$$
T_{\pi}>\sum_{i=1}^{L}\left[S_{i}+\left(\frac{\left(1-\pi_{i}\right) Q_{i}}{P_{1 i}}\right)+\left(\frac{\left(1-\pi_{i}\right) Q_{i} E\left[x_{i}\right]}{P_{2 i}}\right)\right]
$$

Substitute Eq. (5) in Eq. (A-1), we obtain the following:

$$
T_{\pi}>\sum_{i=1}^{L} S_{i}+\sum_{i=1}^{L}\left[\frac{\left(1-\pi_{i}\right) \lambda_{i}}{P_{1 i}}+\frac{\left(1-\pi_{i}\right) \lambda_{i} E\left[x_{i}\right]}{P_{2 i}}\right] T_{\pi}
$$

or:

$$
T_{\pi}\left\{1-\sum_{i=1}^{L}\left[\frac{\left(1-\pi_{i}\right) \lambda_{i}}{P_{1 i}}+\frac{\left(1-\pi_{i}\right) \lambda_{i} E\left[x_{i}\right]}{P_{2 i}}\right]\right\}>\sum_{i=1}^{L} S_{i}
$$

or:

$$
T_{\pi}>\frac{\sum_{i=1}^{L} S_{i}}{\left\{1-\sum_{i=1}^{L}\left[\frac{\left(1-\pi_{i}\right) \lambda_{i}}{P_{1 i}}+\frac{\left(1-\pi_{i}\right) \lambda_{i} E\left[x_{i}\right]}{P_{2 i}}\right]\right\}}
$$

Let:

$$
T_{\text {min }}=\frac{\sum_{i=1}^{L} S_{i}}{\left\{1-\sum_{i=1}^{L}\left[\frac{\left(1-\pi_{i}\right) \lambda_{i}}{P_{1 i}}+\frac{\left(1-\pi_{i}\right) \lambda_{i} E\left[x_{i}\right]}{P_{2 i}}\right]\right\}}
$$

Eq. (A-4) means that the new cycle length $T_{\pi}$ has to be greater than $T_{\min }$ if the summation of $S_{i}$ cannot be ignored. In summary, one should choose $\max \left(T_{\pi}^{*}, T_{\min }\right)[34]$ as the optimal cycle length for the proposed system whether the summation of $S_{i}$ is negligible or not. 
S.W. Chiu, H-C Chen, H-D Lin: Optimal common manufacturing cycle length for a multi-product inventory system with rework and an outside contractor

\subsection{APPENDIX - B}

Table B-1 Changes in average $\pi$ effect on different variables of the proposed system

\begin{tabular}{|c|c|c|c|c|c|c|c|c|c|c|}
\hline $\bar{\pi}$ & $T_{\pi}{ }^{*}$ & $\begin{array}{c}\text { Total cost } \\
E\left[T C U\left(T_{\pi}^{*}\right)\right]\end{array}$ & $\begin{array}{c}\% \\
\text { increase }\end{array}$ & $\begin{array}{c}\text { Sum of } \\
\text { Utilization }\end{array}$ & $\begin{array}{l}\text { Outsourcing } \\
\text { relating cost }\end{array}$ & $\begin{array}{l}\% \text { of } \\
\text { outsourcing } \\
\text { relating } \\
\text { cost in total } \\
\text { cost }\end{array}$ & $\begin{array}{l}\text { In-house } \\
\text { relating } \\
\text { cost }\end{array}$ & $\begin{array}{l}\% \text { of in- } \\
\text { house } \\
\text { relating } \\
\text { cost in } \\
\text { total } \\
\text { cost }\end{array}$ & $\begin{array}{c}\text { Rework } \\
\text { cost } \\
\text { within } \\
\text { in- } \\
\text { house } \\
\text { relating } \\
\text { cost }\end{array}$ & $\begin{array}{l}\% \text { of } \\
\text { rework } \\
\text { cost in } \\
\text { total } \\
\text { cost }\end{array}$ \\
\hline 0.00 & 0.6826 & $\$ 2,005,931$ & - & $71.93 \%$ & $\$ 0$ & $0.00 \%$ & $\$ 2,005,931$ & & $\$ 86,814$ & $4.33 \%$ \\
\hline 0.05 & 0.6865 & $\$ 2,050,501$ & $2.22 \%$ & $68.33 \%$ & $\$ 135,941$ & $6.63 \%$ & $\$ 1,914,560$ & $93.37 \%$ & $\$ 82,375$ & $4.02 \%$ \\
\hline 0.10 & 0.6900 & $\$ 2,069,595$ & 3.17 & & 3 & $11.90 \%$ & $\$ 1,823,331$ & $88.10 \%$ & $\$ 77,945$ & $3.77 \%$ \\
\hline 0.15 & 0.6930 & $\$ 2,088,852$ & $4.13 \%$ & $1.14 \%$ & 04 & $17.07 \%$ & 2,248 & $82.93 \%$ & $\$ 73,522$ & $3.52 \%$ \\
\hline 0.20 & 0.6955 & $\$ 2,108,276$ & $5.10 \%$ & $57.54 \%$ & $\$ 466,963$ & $22.15 \%$ & $\$ 1,641,312$ & $77.85 \%$ & $\$ 69,109$ & $3.28 \%$ \\
\hline 0.25 & 0.6974 & $\$ 2,127,867$ & $6.08 \%$ & $53.94 \%$ & $\$ 577,342$ & $27.13 \%$ & $\$ 1,550,525$ & $72.87 \%$ & $\$ 64,705$ & $3.04 \%$ \\
\hline 0.30 & 0.6989 & $\$ 2,147,627$ & $7.06 \%$ & $50.35 \%$ & $\$ 687,739$ & $32.02 \%$ & $\$ 1,459,887$ & $67.98 \%$ & $\$ 60,311$ & $2.81 \%$ \\
\hline 0.35 & 0.6998 & $\$ 2,167,557$ & $8.06 \%$ & $46.76 \%$ & $\$ 798,156$ & $36.82 \%$ & $\$ 1,369,401$ & $63.18 \%$ & $\$ 55,927$ & $2.58 \%$ \\
\hline 0.40 & 0.7002 & $\$ 2,187,658$ & $9.06 \%$ & $43.16 \%$ & $\$ 908,592$ & $41.53 \%$ & $\$ 1,279,066$ & $58.47 \%$ & $\$ 51,555$ & $2.36 \%$ \\
\hline 0.45 & 0.7001 & $\$ 2,207,930$ & $10.07 \%$ & $39.55 \%$ & $\$ 1,019,047$ & $46.15 \%$ & $\$ 1,188,883$ & $53.85 \%$ & $\$ 47,193$ & $2.14 \%$ \\
\hline 0.50 & 0.6994 & $\$ 2,228,373$ & $11.09 \%$ & $35.96 \%$ & $\$ 1,129,522$ & $50.69 \%$ & $\$ 1,098,851$ & $49.31 \%$ & $\$ 42,843$ & $1.92 \%$ \\
\hline 0.55 & 0.6982 & $\$ 2,248,987$ & $12.12 \%$ & $32.37 \%$ & $\$ 1,240,016$ & $55.14 \%$ & $\$ 1,008,971$ & $44.86 \%$ & $\$ 38,504$ & $1.71 \%$ \\
\hline 0.60 & 0.6964 & $\$ 2,269,770$ & $13.15 \%$ & $28.78 \%$ & $\$ 1,350,529$ & $59.50 \%$ & $\$ 919,241$ & $40.50 \%$ & $\$ 34,178$ & $1.51 \%$ \\
\hline 0.65 & 0.6941 & $2,290,721$ & $14.20 \%$ & $25.17 \%$ & 1,061 & $63.78 \%$ & 560 & $36.22 \%$ & $\$ 29,863$ & $1.30 \%$ \\
\hline 0.70 & 0.6914 & $\$ 2,311,839$ & $15.25 \%$ & $21.58 \%$ & $\$ 1,571,612$ & $67.98 \%$ & 0,228 & $32.02 \%$ & $\$ 25,561$ & $1.11 \%$ \\
\hline 0.75 & 0.6881 & $\$ 2,333,122$ & $16.31 \%$ & $17.99 \%$ & $\$ 1,682,181$ & $72.10 \%$ & 0,941 & $27.90 \%$ & $\$ 21,271$ & $0.91 \%$ \\
\hline 0.792 & 0.6850 & $\$ 2,351,126$ & $17.21 \%$ & & & & & $24.50 \%$ & $\$ 17,676$ & $0.75 \%$ \\
\hline 0.80 & 0.6844 & $\$ 2,354,568$ & $17.38 \%$ & & $\$ 1,792,769$ & $76.14 \%$ & $\$ 561,799$ & $23.86 \%$ & $\$ 16,993$ & $0.72 \%$ \\
\hline 0.85 & 0.6803 & $\$ 2,376,173$ & $18.46 \%$ & $10.79 \%$ & $\$ 1,903,375$ & $80.10 \%$ & $\$ 472,798$ & $19.90 \%$ & $\$ 12,727$ & $0.54 \%$ \\
\hline 0.90 & 0.6757 & $\$ 2,397,935$ & $19.54 \%$ & $7.19 \%$ & $\$ 2,013,998$ & $83.99 \%$ & $\$ 383,936$ & $16.01 \%$ & $\$ 8,473$ & $0.35 \%$ \\
\hline 0.95 & 0.6708 & $\$ 2,419,850$ & $20.63 \%$ & & & $87.80 \%$ & $\$ 295,211$ & $12.20 \%$ & $\$ 4,231$ & $0.17 \%$ \\
\hline 1.00 & 0.6655 & $\$ 2,351,755$ & $17.24 \%$ & $0.00 \%$ & $\$ 2,235,297$ & $95.05 \%$ & $\$ 116,458$ & $4.95 \%$ & $\$ 0$ & $0.00 \%$ \\
\hline
\end{tabular}

\section{ACKNOWLEDGMENTS}

Authors greatly show their appreciation to Ministry of Science and Technology of Taiwan for its kind support (under fund number: MOST 105-2410-H-324-003).

\section{REFERENCES}

[1] K-Y.C. Yu and D.L. Bricker, Analysis of a markov chain model of a multistage manufacturing system with inspection, rejection, and rework, IIE Transactions, Vol. 25, No. 1, pp. 109-112, 1993. https://doi.org/10.1080/07408179308964271

[2] A. Grosfeld-Nir and Y. Gerchak, Multistage production to order with rework capability, Management Science, Vol. 48, No. 5, pp. 652-664, 2002.

https://doi.org/10.1287/mnsc.48.5.652.7802

[3] A.A. Taleizadeh, S.G. Jalali-Naini, H-M. Wee and T-C. Kuo, An imperfect multi-product production system with rework, Scientia Iranica, Vol. 20, No. 3, pp. 811-823, 2013.

https://doi.org/10.1016/i.scient.2012.12.023

[4] C.K. Jaggi, A. Khanna and Nidhi, Effects of inflation and time value of money on an inventory system with deteriorating items and partially backlogged shortages, 
S.W. Chiu, H-C Chen, H-D Lin: Optimal common manufacturing cycle length for a multi-product inventory system with rework and an outside contractor

International Journal of Industrial Engineering Computations, Vol. 7, No. 2, pp. 267-282, 2016. https://doi.org/10.5267/j.ijiec.2015.10.003

[5] Y-S.P. Chiu, H-D. Lin, C-T. Tseng and S.W. Chiu, Determining cycle time for a multiproduct FPR model with rework and an improved delivery policy by alternative approach, International Journal for Engineering Modelling, Vol. 29, No. 1-4, pp. 27-36, 2016.

[6] P. Jawla and S.R. Singh, Multi-item economic production quantity model for imperfect items with multiple production setups and rework under the effect of preservation technology and learning environment, International Journal of Industrial Engineering Computations, Vol. 7, No. 4, pp. 703-716, 2016.

https://doi.org/10.5267/j.ijiec.2016.2.003

[7] H. Ashfaq, I. Hussain and A. Giri, Comparative analysis of old, recycled and new PV modules, Journal of King Saud University - Engineering Sciences, Vol. 29, No. 1, pp. 22-28, 2017. https://doi.org/10.1016/i.jksues.2014.08.004

[8] A. Khanna, A. Kishore and C.K. Jaggi, Strategic production modeling for defective items with imperfect inspection process, rework, and sales return under two-level trade credit, International Journal of Industrial Engineering Computations, Vol. 8, No. 1, pp. 85118, 2017. https://doi.org/10.5267/j.ijiec.2016.7.001

[9] S.M. Kazemi, M. Rabbani, R. Tavakkoli-Moghaddam and F.A. Shahreza, An exact solution for joint optimization of inventory and routing decisions in blood supply chains: A case study, Economic Computation and Economic Cybernetics Studies and Research, Vol. 51, No. 4, pp. 315-333, 2017.

[10] S.W. Chiu, C-J. Liu, Y-R. Chen, and Y-S.P. Chiu, Finite production rate model with backlogging, service level constraint, rework, and random breakdown, International Journal for Engineering Modelling, Vol. 30, No. 1-4, pp. 63-80, 2017.

[11] H.T. Luong and R. Karim, An integrated production inventory model of deteriorating items subject to random machine breakdown with a stochastic repair time, International Journal of Industrial Engineering Computations, Vol. 8, No. 2, pp. 217-236, 2017.

https://doi.org/10.5267/j.ijiec.2016.9.004

[12] Vinnakoti and V.R. Kota, Performance analysis of unified power quality conditioner under different power quality issues using d-q based control, Journal of Engineering Research, Vol. 5, No. 3, pp. 91-109, 2017.

[13] M.J. Rosenblatt and N. Finger, Application of a grouping procedure to a multi-item production system, International Journal of Production Research, Vol. 21, No. 2, 223-229, 1983. https://doi.org/10.1080/00207548308942349

[14] M.J.G. van Eijs, R.M.J. Heuts and J.P.C. Kleijnen, Analysis and comparison of two strategies for multi-item inventory systems with joint replenishment costs, European Journal of Operational Research, Vol. 59, No. 3, pp. 405-412, 1992.

https://doi.org/10.1016/0377-2217(92)90197-H

[15] J-C. Hennet, A common cycle approach to lot-scheduling in multistage manufacturing systems, Production Planning and Control, Vol. 12, No. 4, pp. 362-371, 2001.

https://doi.org/10.1080/09537280010008511 
[16] M.D. Rossetti and A.V. Achlerkar, Evaluation of segmentation techniques for inventory management in large scale multi-item inventory systems, International Journal of Logistics Systems and Management, Vol. 8, No. 4, pp. 403-424, 2011.

https://doi.org/10.1504/IJLSM.2011.039598

[17] Y-S.P. Chiu, M-F. Wu, S.W. Chiu and H-H. Chang, A simplified approach to the multi-item economic production quantity model with scrap, rework, and multi-delivery, Journal of Applied Research and Technology, Vol. 13, No. 4, pp. 472-476, 2015.

https://doi.org/10.1016/i.jart.2015.09.004

[18] K.K. Ikpambese, D.T. Gundu and L.T. Tuleun, Evaluation of palm kernel fibers (PKFs) for production of asbestos-free automotive brake pads, Journal of King Saud University Engineering Sciences, Vol. 28, No. 1, pp. 110-118, 2016.

https://doi.org/10.1016/i.jksues.2014.02.001

[19] Y-S.P. Chiu, Y-T. Hsieh, J-S. Kuo and S.W. Chiu, A delayed differentiation multi-product FPR model with scrap and a multi-delivery policy - I: Using single-machine production scheme, International Journal for Engineering Modelling, Vol. 29, No. 1-4, pp. 37-52, 2016.

[20] Z. Zahedi, T.M.A. Ari Samadhi, S. Suprayogi and A,H, Halim, Integrated batch production and maintenance scheduling for multiple items processed on a deteriorating machine to minimize total production and maintenance costs with due date constraint, International Journal of Industrial Engineering Computations, Vol. 7, No. 2, pp. 229-244, 2016.

https://doi.org/10.5267/j.ijiec.2015.10.006

[21] S.W. Chiu, S-W. Chen, C-K. Chang and Y-S.P. Chiu, Optimization of a multi-product intrasupply chain system with failure in rework, PLoS ONE, Vol. 11, No. 12, art. no. e0167511, pp. 1-17, 2016. https://doi.org/10.1371/journal.pone.0167511

[22] J. Razmi, M.P. Kazerooni and M.S. Sangari, Designing an integrated multi-echelon, multiproduct and multi-period supply chain network with seasonal raw materials, Economic Computation and Economic Cybernetics Studies and Research, Vol. 50, No. 1, pp. 273-290, 2016.

[23] S.W. Chiu, Y-T. Hsieh, Y-S.P. Chiu and M-H. Hwang, A delayed differentiation multiproduct FPR model with scrap and a multi-delivery policy - II: Using two-machine production scheme, International Journal for Engineering Modelling, Vol. 29, No. 1-4, pp. 53-68, 2016.

[24] M. Vujosevic, D. Makajic-Nikolic and P. Pavlovic, A new approach to determination of the most critical multi-state components in multi-state systems, Journal of Applied Engineering Science, Vol. 15, No. 4, pp. 401-405, 2017.

https://doi.org/10.5937/jaes15-15936

[25] A. Ajbar and E. Ali, Study of advanced control of ethanol production through continuous fermentation, Journal of King Saud University - Engineering Sciences, Vol. 29, No. 1, pp. 111, 2017. https://doi.org/10.1016/i.jksues.2015.10.005

[26] J. Hong, A.T.H. Chin and B. Liu, Logistics outsourcing by manufacturers in China: A survey of the industry, Transportation Journal, Vol. 43, No. 1, pp. 17-25, 2004.

[27] C.J.M. Paul and M. Yasar, Outsourcing, productivity, and input composition at the plant level, Canadian Journal of Economics, Vol. 42, No. 2, pp. 422-439, 2009. 
S.W. Chiu, H-C Chen, H-D Lin: Optimal common manufacturing cycle length for a multi-product inventory system with rework and

https://doi.org/10.1111/j.1540-5982.2009.01514.x

[28] K. Pawar and H. Rogers, Contextualising the holistic cost of uncertainty in outsourcing manufacturing supply chains, Production Planning and Control, Vol. 24, No. 7, pp. 607620, 2013. https://doi.org/10.1080/09537287.2012.659872

[29] Y-S.P. Chiu, G-M. Liang and S.W. Chiu, Solving a fabrication lot-size and shipping frequency problem with an outsourcing policy and random scrap, Mathematical and Computational Applications, Vol. 21, No. 4, Art. No. 45, 2016.

\section{https://doi.org/10.3390/mca21040045}

[30] G.N. Kenyon, M.J. Meixell and P.H. Westfall, Production outsourcing and operational performance: An empirical study using secondary data, International Journal of Production Economics, Vol. 171, No. 3, pp. 336-349, 2016.

https://doi.org/10.1016/i.iipe.2015.09.017

[31] Y-S.P. Chiu, C-J. Liu and M-H. Hwang, Optimal batch size considering partial outsourcing plan and rework, Jordan Journal of Mechanical and Industrial Engineering, Vol. 11, No. 3, pp. 195-200, 2017.

[32] A.K. Chakravarty, Offshore outsourcing and ownership of facilities with productivity concerns, IISE Transactions, Vol. 49, No. 6, pp. 642-651, 2017.

https://doi.org/10.1080/24725854.2017.1300357

[33] S.W. Chiu, C-J. Liu, Y-Y. Li and C-L. Chou, Manufacturing lot size and product distribution problem with rework, outsourcing and discontinuous inventory distribution policy, International Journal for Engineering Modelling, Vol. 30, No. 1-4, pp. 49-61, 2017.

[34] S. Nahmias, Production and Operations Analysis, McGraw-Hill Co. Inc., New York, 2009. 